\title{
Ambient temperature and prevalence of diabetes and insulin resistance in the Spanish population: Di@bet.es study
}

\author{
Sergio Valdés 1,2, Viyey Doulatram-Gamgaram1, Ana Lago 1,2, Francisca García Torres ${ }^{3}$, Rocío Badía-Guillén', \\ Gabriel Olveira',2, Albert Goday4, Alfonso Calle-Pascual2,5, Luis Castaño 2,6,15, Conxa Castell7, Elías Delgado8, \\ Edelmiro Menendez ${ }^{8}$, Josep Franch-Nadal2,9, Sonia Gaztambide ${ }^{2,10,15}$, Joan Girbés ${ }^{11}$, Ramón Gomis ${ }^{2,12}$, \\ Emilio Ortega ${ }^{12,13}$, José L Galán-García ${ }^{14}$, Gabriel Aguilera-Venegas ${ }^{14}$, Federico Soriguer ${ }^{1,2}$ and \\ Gemma Rojo-Martínez ${ }^{1,2}$
}

'Department of Endocrinology and Nutrition, Hospital Regional Universitario de Málaga/Universidad de Málaga, IBIMA, Málaga, Spain, ${ }^{2}$ Centro de Investigación Biomédica en Red de Diabetes y Enfermedades Metabólicas Asociadas (CIBERDEM), Instituto de Salud Carlos III, Madrid, Spain, ${ }^{3}$ Department of Endocrinology and Nutrition, Hospital San Pedro, Logroño, Spain, ${ }^{4}$ Department of Endocrinology and Nutrition, Hospital del Mar, Barcelona, Spain, ${ }^{5}$ Department of Endocrinology and Nutrition, Hospital Universitario S. Carlos de Madrid, Madrid, Spain, ${ }^{6}$ Hospital Universitario Cruces, BioCruces Bizkaia, UPV/EHU, Barakaldo, Spain, ${ }^{7}$ Department of Health, Public Health Agency of Catalonia, Barcelona, Spain, ${ }^{8}$ Department of Endocrinology and Nutrition, Hospital Universitario Central de Asturias/ University of Oviedo, Instituto de Investigación Sanitaria del Principado de Asturias (ISPA), Oviedo, Spain, ${ }^{9}$ EAP Raval Sud, Institut Català de la Salut, Red GEDAPS, Primary Care, Unitat de Suport a la Recerca (IDIAP - Fundació Jordi Gol), Barcelona, Spain, ${ }^{10}$ Department of Endocrinology and Nutrition, Hospital Universitario Cruces -BioCruces Bizkaia - UPV-EHU, Baracaldo, Barcelona, Spain, ${ }^{11}$ Diabetes Unit, Hospital Arnau de Vilanova, Valencia, Spain, ${ }^{12}$ Institut d'Investigacions Biomèdiques August Pi i Sunyer (IDIBAPS), Hospital Clínic de Barcelona, Barcelona, Spain, ${ }^{13}$ CIBER de Fisiopatología de la Obesidad y Nutrición (CIBEROBN), Instituto de Salud Carlos III, Madrid, Spain, ${ }^{14}$ Department of Applied Mathematics, University of Málaga, Málaga, Spain, and ${ }^{15}$ Centro de Investigación Biomédica en Red de Enfermedades Raras (CIBERER), Instituto de Salud Carlos III, Madrid, Spain

Correspondence should be addressed to $\mathrm{S}$ Valdés Email sergio.valdes@hotmail.es

\begin{abstract}
Objective: The activity of brown adipose tissue is sensitive to changes in ambient temperature. A lower exposure to cold could result in an increased risk of developing diabetes at population level, although this factor has not yet been sufficiently studied. Design: We studied 5072 subjects, participants in a national, cross-sectional population-based study representative of the Spanish adult population (Di@bet.es study). All subjects underwent a clinical, demographic and lifestyle survey, a physical examination and blood sampling (75 g oral glucose tolerance test). Insulin resistance was estimated with the homeostasis model assessment (HOMA-IR). The mean annual temperature $\left({ }^{\circ} \mathrm{C}\right)$ in each individual municipality was collected from the Spanish National Meteorology Agency.
\end{abstract}

Results: Linear regression analysis showed a significant positive association between mean annual temperature and fasting plasma glucose $(\beta: 0.087, P<0.001), 2 \mathrm{~h}$ plasma glucose $(\beta: 0.049, P=0.008)$ and HOMA-IR $(\beta: 0.046, P=0.008)$ in multivariate adjusted models. Logistic regression analyses controlled by multiple socio-demographic variables, lifestyle, adiposity (BMI) and geographical elevation showed increasing odds ratios for prediabetes (WHO 1999), ORs 1 , $1.26(0.95-1.66), 1.08(0.81-1.44)$ and $1.37(1.01-1.85) P$ for trend $=0.086$, diabetes (WHO 1999) ORs $1,1.05$ (0.79-1.39), $1.20(0.91-1.59)$ and $1.39(1.02-1.90) P=0.037$, and insulin resistance (HOMA-IR $\geq 75$ th percentile of the non-diabetic population): ORs 1, $1.03(0.82-1.30), 1.22(0.96-1.55), 1.26(0.98-1.63)(P$ for trend $=0.046)$ as the mean annual temperature (into quartiles) rose.

Conclusions: Our study reports an association between ambient temperature and the prevalence of dysglycemia and insulin resistance in Spanish adults, consistent with the hypothesis that a lower exposure to cold could be associated with a higher risk of metabolic derangements. 


\section{Introduction}

Brown adipose tissue (BAT) has emerged as a thermogenic tissue capable of energy combustion to generate heat via uncoupling mechanisms $(1,2,3)$.

Activation of human BAT could thus be expected not only to increase energy expenditure, but to also improve glucose homeostasis and insulin sensitivity by increasing the oxidation of triglycerides and glucose as substrates.

BAT is activated by cold exposure $(2,3,4,5,6,7)$ and associative studies have linked higher BAT activity with leanness $(1,4,8)$ and lower glycemia $(8,9)$ in humans.

Moreover, some recent key experiments have shown that short-term cold acclimation under controlled conditions can increase glucose disposal and insulin sensitivity in healthy men $(10,11,12)$ and in type 2 diabetes (DM) subjects (13), even in the absence of significant weight loss. These data support a regulatory role of BAT in glucose homeostasis and insulin sensitivity in humans, as seen in rodent models (14).

Our group has previously reported a positive association between ambient temperature and obesity in Spain (15). In this new report, we aim to explore if there is an association between the thermal environment and glucose metabolism at population level even beyond the BMI.

\section{Subjects and methods}

The Di@bet.es study is a national, cross-sectional, population-based survey that was conducted in 20092010 (16). A cluster sampling design was used to select participants to form a representative random sample of the general non-institutionalized Spanish adult population. The sample was randomly selected from the register of the Spanish Health Care system, which attends more than $99 \%$ of the Spanish population. In the first stage, 100 health centers or their equivalent were selected from all around the country, with a probability proportional to their population size, after which 100 individuals aged $\geq 18$ years were randomly selected from each health center. Of the more than 10000 eligible adults, 55.8\% attended for examination, of whom $9.9 \%$ were excluded (institutionalized, severe disease, pregnancy or recent delivery), resulting in a final sample of 5072 individuals aged $18-93$ years ( $41.6 \%$ men and $58.4 \%$ women).

The research was carried out in accordance with the Declaration of Helsinki (2008) of the Word Medical Association. Written informed consent was obtained from all the participants. The study was approved by the Ethics and Clinical Investigation Committee of the Hospital Regional Universitario de Málaga (Malaga, Spain) in addition to other regional ethics and clinical investigation committees all over Spain.

\section{Variables and procedures}

The participants were invited to attend a single examination visit at their health center. Information was collected using an interviewer-administered structured questionnaire, followed by a physical examination and blood sampling.

Information on age, gender, educational level, ethnicity, family history of diabetes and other sociodemographic variables was obtained by questionnaire. Food consumption was determined by a food frequency questionnaire and adherence to a Mediterranean diet was estimated by a validated 14-item Mediterranean diet score (MedScore) (17). The level of daily physical activity was estimated by the short form of the International Physical Activity Questionnaire (SF-IPAQ) (18). Weight and height were measured by standardized methods. The BMI was calculated. Participants with baseline capillary blood glucose levels lower than $7.8 \mathrm{mmol} / \mathrm{L}$ (Measured by OneTouch ${ }^{\circledR}$ system, Lifescan, Johnson \& Johnson, S.A.) and not receiving treatment for DM underwent a standard oral glucose tolerance test (OGTT), obtaining fasting and 2 -h venous samples. Samples were immediately centrifuged and the serum was frozen until analysis. Serum glucose was measured enzymatically by routine automated methods. Serum insulin was measured by immunochemifluorescence on an Architect I2000 Analyzer (Abbott Laboratories SA). The homeostatic model assessment for insulin resistance index (HOMA-IR) (19) was calculated. The diagnosis of DM and prediabetes was based on the 1999 World Health Organization criteria (20). Insulin resistance was considered if HOMA-IR values were above the 75th percentile of the study populations (excluding subjects with known DM).

The mean annual temperature $\left({ }^{\circ} \mathrm{C}\right)$ data were obtained from the website of the Spanish National Meteorological Agency (21). We introduced more detailed information than in our previous publication (15), this time assessing the temperature data at each individual municipality (rather than at the nearest mean meteorological station). Geographical elevation (in meters) from each site was also recorded. 


\section{Statistical analysis}

The study population was grouped into four categories according to the quartiles of the mean annual temperature at each municipality. The socio-demographic and lifestyle characteristics of the study population as well as other covariates of interest were determined in each quartile. We used linear regression to test the association between mean annual temperature (continuous variable) and fasting plasma glucose (FPG), $2 \mathrm{~h}$ plasma glucose and HOMA-IR in multivariate adjusted models. We also tested the association between mean annual temperature (in quartiles) and the presence of diabetes, prediabetes and insulin resistance in logistic regression models. Linear and logistic regression models were adjusted for multiple covariates (age, gender, ethnicity, education level, family history of diabetes, MedScore and geographical elevation). In two additional models, we sequentially added physical activity (SF-IPAQ) and BMI to the multivariate models to test their significance as mediators of the association. All the covariates included in the models showed a significant association with diabetes $(P<0.05)$ in unilateral logistic regression analysis. Geographical elevation was also included as a covariate as it is associated with ambient temperature, and previous studies have reported an inverse association between diabetes and altitude (22). Reported $P$ values were based on two-sided tests with statistical significance set at 0.05 .

\section{Results}

\section{Clinical characteristics of the study sample according to ambient temperature}

The study sample comprised 5072 individuals with a mean age of 50.4 years (age range: $18-93$ years). $57.1 \%$ were female. Most of the population (93.2\%) were of Caucasian origin. Table 1 shows the clinical characteristics and the distribution of the covariates in the sample classified into quartiles according to the mean annual temperature of the municipality of residence of the participants: Quartile 1 (mean annual temperature between 10.0 and $14.0^{\circ} \mathrm{C}$ ), Quartile 2 (mean annual temperature between 14.1 and $15.1^{\circ} \mathrm{C}$ ), Quartile 3 (mean annual temperature between 15.2 and $17.3^{\circ} \mathrm{C}$ ) and Quartile 4 (mean annual temperature between 17.4 and $21.3^{\circ} \mathrm{C}$ ). There were small differences in the age and sex structure of these groups. There were also small differences in ethnicity and in the education level structure, although no significant trend was found.
The proportion of individuals reporting a family history of diabetes increased as the ambient temperature rose $(P$ for trend $<0.001)$. There were no significant differences between groups according to adherence to MedScore, whereas the proportion of sedentary population was clearly higher in the warmest temperature quartile (55.2\%) than in the rest of the population ( $P$ for difference between groups $<0.001)$. BMI and the proportion of obese persons also increased as the mean ambient temperature rose, as did FPG, insulin levels and HOMA-IR. As expected, there was an inverse relation between ambient temperature and geographical elevation.

\section{Association between mean annual ambient temperature, FPG, $2 \mathrm{~h}$ plasma glucose and HOMA-IR (linear model)}

Table 2 shows the results of the linear correlations between ambient temperature and glucose measurements and HOMA-IR in various linear regression models. The results showed a small, but highly significant positive association between mean annual temperature and FPG in multivariate adjusted models $(\beta$ : 0.102, $P<0.001)$, which remained relatively unchanged after the addition of IPAQ $(\beta: 0.102, P<0.001)$ and BMI $(\beta: 0.091, P<0.001)$ in the models. The associations between ambient temperature and $2 \mathrm{~h}$ plasma glucose and HOMA-IR followed the same trend $(\beta$ : 0.063, $P<0.001$ and $\beta: 0.070, P<0.001$ in multivariate models respectively) and were also relatively unchanged with the addition of IPAQ $(\beta 0.058, P<0.001$ and $\beta: 0.058, P=0.001$ respectively), and mildly reduced with the additional inclusion of BMI $(\beta$ : 0.048, $P<0.001$ and $\beta$ : $0.040, P=0.040$ ).

\section{Association between mean annual ambient temperature and the prevalence of prediabetes, diabetes and insulin resistance (logistic regression model)}

Table 3 shows the prevalence and the multivariate-adjusted odds ratios (OR) for prediabetes, diabetes and insulin resistance in the study population divided according to their mean annual temperature quartile. The prevalence and multivariate adjusted ORs of prediabetes increased across the ambient temperature groups (ORs: 1.27 (0.97-1.67), $1.11(0.84-1.47)$ and $1.56(1.16-2.09)$ in quartiles 2,3 and 4 vs reference $P$ for trend $=0.014$ ), which were only modestly reduced after the inclusion of physical activity (ORs: 1.27 (0.96-1.66), $1.12(0.84-1.48)$ and 
Table 1 Clinical characteristics of the study sample according to ambient temperature quartiles. Data are presented as mean or $\%$ and $95 \% \mathrm{Cl}$.

\begin{tabular}{l} 
Characteristics \\
\hline Number \\
Age (years) \\
Gender (female) (\%) \\
Ethnicity (Caucasian) (\%) \\
Educational level (\%) \\
No studies \\
Basic \\
High school-college \\
Family history of DM (\%) \\
Mediterranean diet score \\
Mediterranean diet score $<7$ (\%) \\
Physical activity (SF-IPAQ) (\%) \\
Low \\
Medium \\
High \\
Body mass index \\
Obesity (\%) \\
Fasting plasma glucose (mg/dL) \\
2h plasma glucose (mg/dL) \\
Fasting insulin ( $\mu$ U/mL) \\
HOMA-IR \\
Geographical elevation (m)
\end{tabular}

\begin{tabular}{|c|c|}
\hline & Mean annual \\
\hline Quartile 1 & Quartile 2 \\
\hline 1308 & 1236 \\
\hline $52.5(51.6-53.5)$ & $51.1(50.1-52.0)$ \\
\hline $55.5(52.8-58.2)$ & $55.3(52.4-58.1)$ \\
\hline 96.9 (95.8-97.7) & $89.3(87.5-91.0)$ \\
\hline $13.8(12.0-15.8)$ & $9.9(8.3-11.7)$ \\
\hline $48.8(46.0-51.5)$ & $45.2(42.3-48.0)$ \\
\hline $37.4(34.8-40.1)$ & $44.9(42.1-47.7)$ \\
\hline $30.5(28.0-33.2)$ & $33.1(30.4-35.8)$ \\
\hline 7.8 (7.7-7.9) & $7.8(7.7-7.9)$ \\
\hline $20.7(18.5-23.0)$ & $19.7(17.5-22.0)$ \\
\hline $40.6(37.9-43.3)$ & $40.6(37.9-43.4)$ \\
\hline $39.8(37.2-42.5)$ & $39.5(36.7-42.3)$ \\
\hline $19.7(17.5-21.9)$ & $19.9(17.7-22.2)$ \\
\hline $27.9(27.6-28.2)$ & $27.7(27.4-28.0)$ \\
\hline $28.7(26.2-31.2)$ & $28.2(25.7-30.8)$ \\
\hline $93.4(92.5-94.3)$ & $91.0(90.0-92.0)$ \\
\hline $108.9(106.0-111.8)$ & $113.6(110.1-117.0)$ \\
\hline $8.4(8.0-8.7)$ & $8.6(8.3-8.9)$ \\
\hline $2.0(1.9-2.1)$ & $2.0(1.9-2.1)$ \\
\hline $543.1(525.8-560.4)$ & $442.4(427.7-457.0)$ \\
\hline
\end{tabular}

\begin{tabular}{c} 
temperature \\
\hline Quartile 3 \\
\hline 1397 \\
$49.8(48.9-50.6)$ \\
$57.3(54.7-59.9)$ \\
$91.2(89.6-92.6)$ \\
\\
$14.4(12.6-16.3)$ \\
$50.2(47.5-52.8)$ \\
$35.4(32.9-38.0)$ \\
$38.5(35.9-41.2)$ \\
$7.7(7.6-7.8)$ \\
$24.0(21.7-26.3)$ \\
$36.3(33.8-38.9)$ \\
$28.9(26.6-31.4)$ \\
$34.7(32.2-37.3)$ \\
$28.2(27.9-28.4)$ \\
$31.5(29.1-34.0)$ \\
$94.5(93.2-95.7)$ \\
$111.2(108.0-114.4)$ \\
$9.0(8.5-9.6)$ \\
$2.2(2.0-2.4)$ \\
$178.3(166.4-190.2)$
\end{tabular}

\begin{tabular}{c} 
\\
\hline Quartile 4 \\
\hline 1131 \\
$48.1(47.1-49.0)$ \\
$60.8(57.9-63.7)$ \\
$95.6(94.2-96.7)$ \\
\\
$13.9(11.9-16.1)$ \\
$46.9(44.0-49.9)$ \\
$39.1(36.3-42.1)$ \\
$43.4(40.4-46.4)$ \\
$7.8(7.7-7.9)$ \\
$21.1(18.7-23.6)$ \\
\\
$55.2(52.2-58.1)$ \\
$28.0(25.4-30.8)$ \\
$16.8(14.6-19.1)$ \\
$28.6(28.3-28.9)$ \\
$34.3(31.5-37.2)$ \\
$97.6(96.4-98.8)$ \\
$114.2(110.9-117.5)$ \\
$9.2(8.8-9.6)$ \\
$2.3(2.2-2.4)$ \\
$105.2(98.0-112.4)$
\end{tabular}

\begin{tabular}{|c|c|}
\hline $\begin{array}{l}P \text { value for } \\
\text { difference }\end{array}$ & $\begin{array}{l}\text { P value } \\
\text { for trend }\end{array}$ \\
\hline$<0.001$ & $<0.001$ \\
\hline 0.023 & 0.005 \\
\hline$<0.001$ & 0.275 \\
\hline$<0.001$ & 0.299 \\
\hline$<0.001$ & $<0.001$ \\
\hline 0.392 & 0.278 \\
\hline 0.045 & 0.255 \\
\hline$<0.001$ & 0.010 \\
\hline$<0.001$ & $<0.001$ \\
\hline 0.004 & 0.001 \\
\hline$<0.001$ & $<0.001$ \\
\hline 0.089 & 0.059 \\
\hline 0.017 & 0.002 \\
\hline$<0.001$ & $<0.001$ \\
\hline$<0.001$ & $<0.001$ \\
\hline
\end{tabular}

Quartile 1: $10.0-14.0^{\circ} \mathrm{C}$; Quartile 2: $14.1-15.1^{\circ} \mathrm{C}$; Quartile 3: $15.2-17.3^{\circ} \mathrm{C}$; Quartile 4: $17.4-21.3^{\circ} \mathrm{C}$.

"Subjects with known diabetes were excluded for the analysis.

1.48 (1.10-1.99) vs reference $P$ for trend $=P$ for trend $=0.029)$ and BMI (ORs: 1.26 (0.95-1.66), 1.08 (0.81-1.44) and 1.37 (1.01-1.85) vs reference $P$ for trend $=0.086)$. The prevalence of diabetes also increased as the temperature rose, showing a significant linear trend in multivariate adjusted models (ORs: 1.08 (0.82-1.43), 1.33 (1.01-1.75) and $1.70(1.26-2.29)$ in quartiles 2-4 vs reference $P=0.001$ ), and in multivariate+IPAQ (ORs: 1.06 (0.81-1.40), 1.33 (1.01-1.76) and 1.54 (1.14-2.09) $P=0.003)$, and in the complete multivariate model with IPAQ and BMI (ORs: 1.05 (0.79-1.39), 1.20 (0.91-1.59), 1.39 (1.02-1.90) $P=0.037)$.

Ambient temperature was also associated with insulin resistance, with ORs of 1.11 (0.90-1.37), 1.24
(1.00-1.53) and $1.63(1.30-2.04)$ and $P$ for trend $<0.001$ in the multivariate model, with a modest decrease in the association after the inclusion of physical activity (ORs of 1.10 (0.89-1.36), 1.25 (1.01-1.55) and 1.45 (1.15-1.82) $P$ for trend $=0.001$ ) and physical activity + BMI (ORs of 1.03 (0.82-1.30), $1.22(0.96-1.54)$ and $1.26(0.98-1.63) P$ for trend $=0.046)$.

\section{Discussion}

The results of this nationally representative epidemiological study showed a positive association between ambient temperature and measures of glucose

Table 2 Correlation between mean annual ambient temperature $\left({ }^{\circ} \mathrm{C}\right)$ and fasting plasm glucose (FPG), $2 \mathrm{~h}$ plasma glucose (2hPG) and HOMA-IR.

\begin{tabular}{|c|c|c|c|c|c|c|c|c|}
\hline \multirow[b]{2}{*}{ Correlation parameters } & \multicolumn{2}{|l|}{ Crude } & \multicolumn{2}{|c|}{ Multivariate" } & \multicolumn{2}{|c|}{ Multivariate ${ }^{\#}$ + IPAQ } & \multicolumn{2}{|c|}{ Multivariate" + IPAQ + BMI } \\
\hline & $\beta$ standardized & $P$ & $\beta$ standardized & $P$ & $\beta$ standardized & $P$ & $\beta$ standardized & $P$ \\
\hline \multicolumn{9}{|c|}{ Mean annual temperature and } \\
\hline$-F P G$ & 0.095 & $<0.001$ & 0.102 & $<0.001$ & 0.102 & $<0.001$ & 0.091 & $<0.001$ \\
\hline$-2 h P G$ & 0.020 & 0.257 & 0.063 & $<0.001$ & 0.058 & $<0.001$ & 0.048 & 0.010 \\
\hline -HOMA-IR & 0.060 & $<0.001$ & 0.070 & $<0.001$ & 0.058 & 0.001 & 0.040 & 0.020 \\
\hline
\end{tabular}

$\beta$ standardized coefficients and $P$ values were calculated by linear regression. Mean annual temperature was introduced in the model as a continuous variable. Subjects with known diabetes $(n=480)$ were excluded for the analysis.

\#Multivariate model: adjusted to age, gender, ethnicity, education level, family history of diabetes, MedScore and geographical elevation.

BMI, body mass index; IPAQ, International Physical Activity Questionnaire (18). 
Table 3 Prevalence (\%) and multivariate adjusted odd ratios (ORs) for prediabetes, diabetes and insulin resistance in the study population divided according to mean annual ambient temperature quartiles.

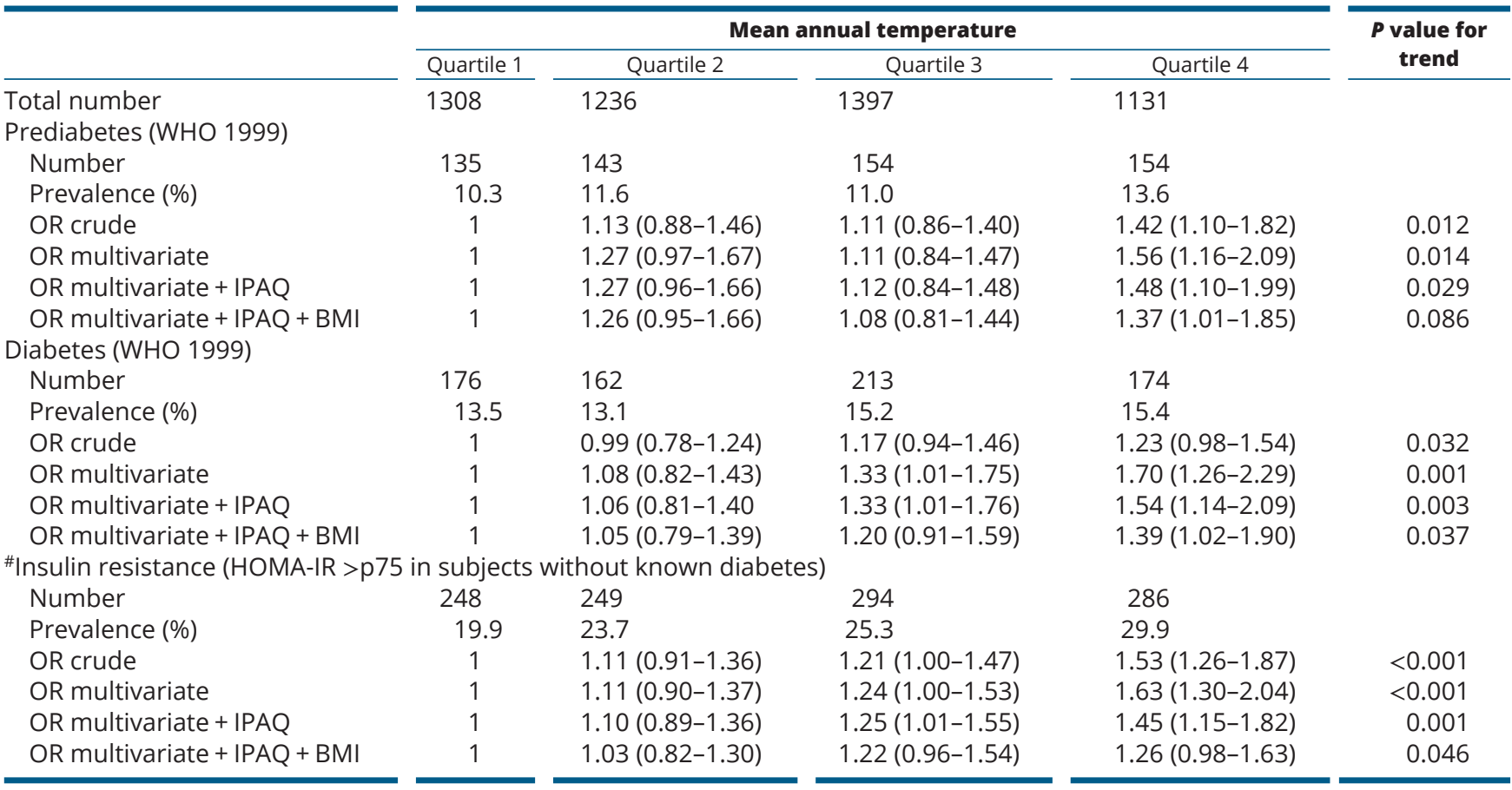

Multivariate ORs and $P$ values were calculated by logistic regression. Multivariate model: adjusted to age, gender, ethnicity, education level, family history of diabetes, MedScore, and geographical elevation. Quartile 1: $10.0-14.0^{\circ} \mathrm{C}$; Quartile 2: $14.1-15.1^{\circ} \mathrm{C}$; Quartile 3: $15.2-17.3^{\circ} \mathrm{C}$; Quartile 4: $17.4-21.3^{\circ} \mathrm{C}$. \#For this analysis subjects with known diabetes $(n=480)$ were excluded. The 75th percentile of the distribution of HOMA-IR in the study population without known diabetes was 2.51 .

BMI, body mass index; IPAQ, International Physical Activity Questionnaire (18).

metabolism, as well as the prevalence of prediabetes, diabetes and insulin resistance in Spanish adults that remained after the adjustment for multiple demographic and lifestyle variables, BMI and elevation.

This study expands the data of a previous publication of our group reporting the association between ambient temperature and obesity (15) and suggests a potential relation between the thermal environment and glucose metabolism even beyond body weight. Although our results cannot be interpreted as causal, the persistence of an association after adjustment for physical activity measurements and BMI leads us to hypothesize that a potential explanatory mechanism for this association could rely on differences in BAT activity sensitive to changes in ambient temperature. In fact, it is well known that colder ambient temperatures stimulate brown adipose tissue $(2,3,4,5,6,7)$. Since BAT is capable of disposing of large quantities of glucose and lipids (23, $24)$, activation of human BAT could thus be expected not only to increase energy expenditure, but also to improve glucose homeostasis and insulin resistance. Lee et al., in a 'proof-of-concept' study, showed that sequential monthly acclimation in a temperature-controlled research facility, modulated BAT reversibly and increased diet-induced thermogenesis and postprandial insulin sensitivity of five healthy men, in the absence of significant weight loss (10). Accordingly, Chondronikola et al. studied seven BATpositive men and five BAT-negative men under thermoneutral conditions and after prolonged $(5-8 \mathrm{~h})$ cold exposure and showed that cold exposure significantly increased resting energy expenditure, whole body glucose disposal, plasma glucose oxidation and insulin sensitivity in the BAT-positive group only (11). Iwen et al. exposed 15 healthy men to thermo-neutrality $\left(22^{\circ} \mathrm{C}\right)$ and to moderate cold $\left(18.06^{\circ} \mathrm{C}\right)$ by the use of a water-perfused whole body suit. Peripheral glucose uptake and insulin sensitivity significantly improved by $20 \%$ (12). Hansen et al. reported an increase in peripheral insulin sensitivity by $\sim 43 \%$ in eight type 2 diabetes subjects after exposure to 10 days of cold acclimation $\left(14-15^{\circ} \mathrm{C}\right)$ while body weight was unaltered (13).

These data strongly support that moderate cold exposure may exert anti-diabetic effects in humans via activation of BAT activity. Our results are consistent with this concept, supporting the hypothesis that a lower exposure to cold could be associated with a higher risk 
of dysglycemia and insulin resistance at population level, even after controlling for other demographic and lifestyle factors and adiposity measurements. Strikingly, the magnitude of the association we report in our study (a nearly $40 \%$ increase in the OR for prediabetes and diabetes and around a $25 \%$ increase in the OR for insulin resistance in subjects exposed to the warmest temperature quartile $\left(17.4-21.3^{\circ} \mathrm{C}\right)$ compared to reference $\left(10.0-14.0^{\circ} \mathrm{C}\right)$ ), fairly correlates with the magnitude of the increase in glucose disposal and insulin sensitivity after cold acclimation seen in previous experimental studies $(10,11,12,13)$.

Besides BAT, physical activity could be another potential mediator in the association. In fact, previous research has provided support that physical activity can be influenced by the physical environmental characteristics (25). Although in general a positive correlation between outdoor temperature and physical activity has been described, extreme heat has also been recognized as a strong deterrent to outdoor activities (26). The proportion of sedentary population in our study was clearly higher in the warmest temperature quartile (55.2\%) in which median temperatures $>25^{\circ}$ and maximum temperatures $>30^{\circ}$ during the summer months are common (21). This could have led to more sedentary behavior, although the influence of other cultural and/or educational factors (besides ambient temperature) on these differences cannot be discarded. The effect of this factor as a mediator in the association between temperature and diabetes seems however to be minimal in view of the small modifications of the results after the adjustment of the data for the physical activity measurements.

A negative relation between ambient temperature and food intake has also been described, at least in animal models (27). The results of the food frequency questionnaire in our study showed no difference with regard to adherence to a Mediterranean diet between groups, so at least we can confirm that the diet composition was very similar. It is noteworthy that this factor, if anything, would have counter balanced the effect of ambient temperature on diabetes outcomes.

Finally the progressive increase in the prevalence of subjects reporting a family history of diabetes across the temperature groups (Table 1) could even indicate a genetic influence in the association. According to the cold climate gene hypotheses, the adaptation to chronic cold in ancient populations may have led to a combination of genes to provide an additional survival advantage, and may also have provided less susceptibility to T2D and other metabolic diseases $(28,29)$. A recent report has linked the FTO region (which harbors the strongest genetic association with obesity and diabetes), with white adipocyte browning and thermogenesis in humans (30) so that a temperature-gene interaction cannot be discarded. We do not have data to confirm or reject this hypothesis, but we are currently undertaking further genetic studies to deepen our knowledge of these associations.

We reviewed previous epidemiological studies reporting associations between temperature and diabetes outcomes and found two recent reports with results that are in line with our data. Speakman et al. used county level data for obesity and diabetes prevalence across the United States and matched this to county level ambient temperature data. Average ambient temperature explained $5.7 \%$ of the spatial variation in obesity and $29.6 \%$ of the spatial variation in type 2 diabetes prevalence. Even when correcting for obesity, poverty and race, ambient temperature explained $12.4 \%$ of the variation in the prevalence of type 2 diabetes (30). Accordingly, Blauw et al. examined the association between outdoor temperature and diabetes incidence in the USA as well as the prevalence of glucose intolerance worldwide. The results showed that for every $1^{\circ} \mathrm{C}$ increase in temperature, age-adjusted diabetes incidence increased by 0.314 (95\% CI: 0.194 $0.434)$ per 1000 . Similarly, the worldwide prevalence of glucose intolerance increased by $0.170 \%$ (95\% CI: $0.107-$ $0.234 \%)$. These associations persisted after adjustment for obesity (31). Remarkably, in our study, we were able to replicate these previous results using individual level data (rather than state level or country level) on weight, BMI, FPG, 2hPG, insulin and a number of demographic and lifestyle factors, along with the mean annual temperature of the municipality of residence of each participant, which probably allowed us to perform a more robust multivariate adjustment of the data. It is well known that aggregate data inference is especially prone to bias and confounding (32). The individual data analysis we provide in our study, probably provides greater evidence for the existence of a true association between temperature and diabetes. As in previous reports, the main limitation of this study lies in the observational cross-sectional nature of the analyses, so that we cannot establish causal associations or exclude residual confounding.

In summary, this study reports an association between ambient temperature and the prevalence of dysglycemia and insulin resistance in Spanish adults, which is concordant with the hypothesis that a lower exposure to cold could be associated with a higher risk of metabolic derangements. These findings emphasize the need for further research concerning the effect of temperature on 
glucose homeostasis in humans, in the context of global climate change and the present diabetes pandemic.

\section{Declaration of interest}

The authors declare that there is no conflict of interest that could be perceived as prejudicing the impartiality of this study.

\section{Funding}

The research reported here was funded by CIBERDEM (Ministerio de Economía, Industria y Competitividad-ISCIII), Ministerio de Sanidad, Servicios Sociales e Igualdad-ISCIII, Instituto de Salud Carlos III (PI14/00710, $\mathrm{PI} 14 / 01104, \mathrm{PI} 14 / 00970, \mathrm{PI} 14 / 00874, \mathrm{PI} 14 / 00465$ and PI17/02136), European Regional Development Fund (ERDF) 'A way to build Europe'.

\section{Acknowledgements}

The authors wish to acknowledge the primary care managers and personnel of the participating health centers, all the nurses and dietitians who made the Di@bet.es study field work possible (I Alonso, A Arocas, R Badia, C M Bixquert, N Brito, D Chaves, A Cobo, L Esquius, I Guillén, E Mañas, A M Megido, N Ojeda, R M Suarep and M D Zomeño). They would especially like to thank all the people who participated voluntarily in the study. They are indebted to the Andalusian Biobank and IDIBAPS Biobank, integrated in the Spanish National Biobank Network, for the sample procurement.

\section{References}

1 Cypess AM, Lehman S, Williams G, Tal I, Rodman D, Goldfine AB, Kuo FC, Palmer EL, Tseng YH, Doria A et al. Identification and importance of brown adipose tissue in adult humans. New England Journal of Medicine 2009360 1509-1517. (https://doi.org/10.1056/ NEJMoa0810780)

2 Van Marken Lichtenbelt WD, Vanhommerig JW, Smulders NM, Drossaerts JM, Kemerink GJ, Bouvy ND, Schrauwen P \& Teule GJ. Cold-activated brown adipose tissue in healthy men. New England Journal of Medicine 2009360 1500-1508. (https://doi.org/10.1056/ NEJMoa0808718)

3 Virtanen KA, Lidell ME, Orava J, Heglind M, Westergren R, Niemi T, Taittonen M, Laine J, Savisto NJ, Enerbäck S et al. Functional brown adipose tissue in healthy adults. New England Journal of Medicine 2009 360 1518-1525. (https://doi.org/10.1056/NEJMoa0808949)

4 Saito M, Okamatsu-Ogura Y, Matsushita M, Watanabe K, Yoneshiro T, Nio-Kobayashi J, Iwanaga T, Miyagawa M, Kameya T, Nakada K et al. High incidence of metabolically active brown adipose tissue in healthy adult humans: effects of cold exposure and adiposity. Diabetes 200958 1526-1531. (https://doi.org/10.2337/db09-0530)

5 Chen KY, Brychta RJ, Linderman JD, Smith S, Courville A, Dieckmann W, Herscovitch P, Millo CM, Remaley A, Lee P et al. Brown fat activation mediates cold-induced thermogenesis in adult humans in response to a mild decrease in ambient temperature. Journal of Clinical Endocrinology and Metabolism 201398 E1218-E1223. (https://doi.org/10.1210/jc.2012-4213)

6 Van der Lans AA, Hoeks J, Brans B, Vijgen GH, Visser MG, Vosselman MJ, Hansen J, Jörgensen JA, Wu J, Mottaghy FM et al. Cold acclimation recruits human brown fat and increases nonshivering thermogenesis. Journal of Clinical Investigation 2013 123 3395-3403. (https://doi.org/10.1172/JCI68993)

7 Yoneshiro T, Aita S, Matsushita M, Kayahara T, Kameya T, Kawai Y, Iwanaga $\mathrm{T} \&$ Saito $\mathrm{M}$. Recruited brown adipose tissue as an antiobesity agent in humans. Journal of Clinical Investigation 2013 123 3404-3408. (https://doi.org/10.1172/JCI67803)
8 Lee P, Greenfield JR, Ho KK \& Fulham MJ. A critical appraisal of the prevalence and metabolic significance of brown adipose tissue in adult humans. American Journal of Physiology: Endocrinology and Metabolism 2010299 E601-E606. (https://doi.org/10.1152/ ajpendo.00298.2010)

9 Matsushita M, Yoneshiro T, Aita S, Kameya T, Sugie H \& Saito M. Impact of brown adipose tissue on body fatness and glucose metabolism in healthy humans. International Journal of Obesity 2014 38 812-817. (https://doi.org/10.1038/ijo.2013.206)

10 Lee P, Smith S, Linderman J, Courville AB, Brychta RJ, Dieckmann W, Werner CD, Chen KY \& Celi FS. Temperature-acclimated brown adipose tissue modulates insulin sensitivity in humans. Diabetes 2014 63 3686-3698. (https://doi.org/10.2337/db14-0513)

11 Chondronikola M, Volpi E, Børsheim E, Porter C, Annamalai P, Enerbäck S, Lidell ME, Saraf MK, Labbe SM, Hurren NM et al. Brown adipose tissue improves whole-body glucose homeostasis and insulin sensitivity in humans. Diabetes 201463 4089-4099. (https://doi. org/10.2337/db14-0746)

12 Iwen KA, Backhaus J, Cassens M, Waltl M, Hedesan OC, Merkel M, Heeren J, Sina C, Rademacher L, Windjäger A et al. Cold-induced brown adipose tissue activity alters plasma fatty acids and improves glucose metabolism in men. Journal of Clinical Endocrinology and Metabolism 2017102 4226-4234. (https://doi.org/10.1210/jc.201701250)

13 Hanssen MJ, Hoeks J, Brans B, van der Lans AA, Schaart G, van den Driessche JJ, Jörgensen JA, Boekschoten MV, Hesselink MK, Havekes B et al. Short-term cold acclimation improves insulin sensitivity in patients with type 2 diabetes mellitus. Nature Medicine 201521 863-865. (https://doi.org/10.1038/nm.3891)

14 Stanford KI, Middelbeek RJ, Townsend KL, An D, Nygaard EB, Hitchcox KM, Markan KR, Nakano K, Hirshman MF, Tseng YH et al. Brown adipose tissue regulates glucose homeostasis and insulin sensitivity. Journal of Clinical Investigation 2013123 215-223. (https://doi.org/10.1172/JCI62308)

15 Valdés S, Maldonado-Araque C, García-Torres F, Goday A, BoschComas A, Bordiú E, Calle-Pascual A, Carmena R, Casamitjana R, Castaño L et al. Ambient temperature and prevalence of obesity in the Spanish population: the Di@bet.es study. Obesity 201422 2328-2332. (https://doi.org/10.1002/oby.20866)

16 Soriguer F, Goday A, Bosch-Comas A, Bordiú E, Calle-Pascual A, Carmena R, Casamitjana R, Castaño L, Castell C, Catalá M et al. Prevalence of diabetes mellitus and impaired glucose regulation in Spain: the Di@bet.es Study. Diabetologia 201255 88-93. (https://doi. org/10.1007/s00125-011-2336-9)

17 Schröder H, Fitó M, Estruch R, Martínez-González MA, Corella D, Salas-Salvadó J, Lamuela-Raventós R, Ros E, Salaverría I, Fiol M et al. A short screener is valid for assessing Mediterranean diet adherence among older Spanish men and women. Journal of Nutrition $2011 \mathbf{1 4 1}$ 1140-1145. (https://doi.org/10.3945/jn.110.135566)

18 IPAQ Group. International Physical Activity Questionarie. Web site. (available at: www.ipaq.ki.se). Accessed on 27 January 2019.

19 Matthews DR, Hosker JP, Rudenski AS, Naylor BA, Treacher DF \& Turner RC. Homeostasis model assessment: insulin resistance and beta-cell function from fasting plasma glucose and insulin concentrations in man. Diabetologia 198528 412-419. (https://doi. org/10.1007/BF00280883)

20 World Health Organization. Definition, diagnosis and classification of diabetes mellitus and its complications: report of a WHO consultation. Part 1: diagnosis and classification of diabetes mellitus. Diabetic Medicine 199815 539-553.

21 Agencia Estatal de Metereologia. Web site. (available at: www.aemet. es). Accessed on 27 January 2019.

22 Woolcott OO, Castillo OA, Gutierrez C, Elashoff RM, Stefanovski D \& Bergman RN. Inverse association between diabetes and altitude: a cross-sectional study in the adult population of the United States. Obesity 201422 2080-2090. (https://doi.org/10.1002/oby.20800) 
23 Orava J, Nuutila P, Lidell ME, Oikonen V, Noponen T, Viljanen T, Scheinin M, Taittonen M, Niemi T, Enerbäck S et al. Different metabolic responses of human brown adipose tissue to activation by cold and insulin. Cell Metabolism 201114 272-279. (https://doi. org/10.1016/j.cmet.2011.06.012)

24 Taittonen M, Niemi T, Enerbäck S et al. Different metabolic responses of human brown adipose tissue to activation by cold and insulin. Cell Metabolism 20113 272-279. (https://doi.org/10.1016/j. cmet.2011.06.012)

25 Ouellet V, Labbé SM, Blondin DP, Phoenix S, Guérin B, Haman F, Turcotte EE, Richard D \& Carpentier AC. Brown adipose tissue oxidative metabolism contributes to energy expenditure during acute cold exposure in humans. Journal of Clinical Investigation 2012122 545-552. (https://doi.org/10.1172/JCI60433)

26 Ouellet V, Labbé SM, Blondin DP, Phoenix S, Guérin B, Haman F, Turcotte EE, Richard D \& Carpentier AC. Brown adipose tissue oxidative metabolism contributes to energy expenditure during acute cold exposure in humans. Journal of Clinical Investigation 2012122 545-552. (https://doi.org/10.1172/JCI60433)

27 Tucker P \& Gilliland J. The effect of season and weather on physical activity: a systematic review. Public Health 2007121 909-922. (https://doi.org/10.1016/j.puhe.2007.04.009)

28 Ridgers ND, Salmon J \& Timperio A. Too hot to move? Objectively assessed seasonal changes in Australian children's physical activity. International Journal of Behavioral Nutrition and Physical Activity 2015 12 77. (https://doi.org/10.1186/s12966-015-0245-x)

29 Suwanapaporn P, Chaiyabutr N \& Thammacharoen S. A low degree of high ambient temperature decreased food intake and activated median preoptic and arcuate nuclei. Physiology and Behavior 2017 181 16-22. (https://doi.org/10.1016/j.physbeh.2017.08.027)

30 Fridlyand LE \& Philipson LH. Cold climate genes and the prevalence of type 2 diabetes mellitus. Medical Hypotheses 200667 1034-1041. (https://doi.org/10.1016/j.mehy.2006.04.057)

31 Lappalainen T, Salmela E, Andersen PM, Dahlman-Wright K, Sistonen P, Savontaus ML, Schreiber S, Lahermo P \& Kere J. Genomic landscape of positive natural selection in northern European populations. European Journal of Human Genetics 201018 471-478. (https://doi.org/10.1038/ejhg.2009.184)

32 Claussnitzer M, Dankel SN, Kim KH, Quon G, Meuleman W, Haugen C, Glunk V, Sousa IS, Beaudry JL, Puviindran V et al. FTO obesity variant circuitry and adipocyte browning in humans. New England Journal of Medicine 2015373 895-907. (https://doi. org/10.1056/NEJMoa1502214)

33 Speakman JR \& Heidari-Bakavoli S. Type 2 diabetes, but not obesity, prevalence is positively associated with ambient temperature. Scientific Reports 20166 30409. (https://doi. org/10.1038/srep30409)

34 Blauw LL, Aziz NA, Tannemaat MR, Blauw CA, de Craen AJ, Pijl H \& Rensen PC. Diabetes incidence and glucose intolerance prevalence increase with higher outdoor temperature. BMJ Open Diabetes Research and Care 2017205 e000317. (https://doi.org/10.1136/ bmjdrc-2016-000317)

35 Von Korff M, Koepsell TD, Curry S \& Diehr P. Multi-level analysis in epidemiologic research on health behaviors and outcomes. American Journal of Epidemiology 1992135 1077-1082. (https://doi. org/10.1093/oxfordjournals.aje.a116207)

Received 9 October 2018

Revised version received 27 February 2019

Accepted 5 March 2019 